Article

\title{
In Vivo Biological Evaluation of Orthodontically Moved Incisors after Replantation
}

\author{
Jose de Albuquerque Calasans-Maia ${ }^{1, *} \mathbb{C}$, Monica Diuana Calasans-Maia ${ }^{2}$, \\ Maria Bernadete Sasso Stuani ${ }^{3}$, Adriana Terezinha Neves Novellino Alves ${ }^{4}$, \\ Pietro Montemezzi ${ }^{5}$, Carlos Fernando de Almeida Barros Mourão ${ }^{6}{ }^{(\mathbb{6}}$, Julio Pedra e Cal-Neto ${ }^{7}$ \\ and Antonio Carlos de Oliviera Ruellas ${ }^{8}$ \\ 1 Orthodontics Department, Dentistry School, Universidade Federal Fluminense, \\ Rio de Janeiro 24020-140, Brazil \\ 2 Oral Surgery Department, Dentistry School, Universidade Federal Fluminense, \\ Rio de Janeiro 24020-140, Brazil; monicacalasans@id.uff.br \\ 3 Orthodontics Department, Dentistry School, Universidade de São Paulo Ribeirão Preto, Ribeirão Preto \\ 14049-900, Brazil; bernadete@forp.usp.br \\ 4 Oral Diagnosis Department, Dentistry School, Universidade Federal Fluminense, \\ Rio de Janeiro 24020-140, Brazil; aterezinha@gmail.com \\ 5 Private Practice, 24128 Bergamo, Italy; m.montemezzi@libero.it \\ 6 Post-Graduation Program, Dentistry School, Universidade Federal Fluminense, \\ Rio de Janeiro 24020-140, Brazil; mouraocf@gmail.com \\ 7 Orthodontics Department, Instituto de Saúde de Nova Friburgo, Universidade Federal Fluminense, \\ Rio de Janeiro 28625-650, Brazil; juliocalneto@yahoo.com.br \\ 8 Orthodontics Department, Dentistry School, Universidade Federal do Rio de Janeiro, \\ Rio de Janeiro 21941-617, Brazil; aruellas@umich.edu \\ * Correspondence: josecalasans@id.uff.br; Tel.: +55-21-2629-9812
}

Received: 8 July 2020; Accepted: 14 August 2020; Published: 20 August 2020

\begin{abstract}
Background and Objectives: There is still considerable controversy regarding the possibility of submitting replanted teeth to orthodontic movement $(\mathrm{OM})$. The purpose of the present study was to evaluate the tissue response after orthodontic movement on replanted teeth. Materials and Methods: Sixty Wistar rats were randomly assigned to four groups ( $n=15)$ : G1, replantation without OM after 30 days; G2, replantation with OM after 30 days; G3, replantation without OM after 60 days, and G4, replantation with OM after 60 days. The maxillary left central incisors were extracted and the teeth were stored in milk media. After $30 \mathrm{~min}$, the teeth were replanted and fixed with non-rigid immobilization. All specimens were observed after 30 and 60 days of replantation and then subdivided into two subgroups (with OM or without $\mathrm{OM}$ ). The animals were euthanized after seven days of the OM started, and the maxillary bone blocks were processed for histological evaluation. Results: The histological results showed periodontal ligament repair in both periods studied without OM; however, ankylosis and root resorption was seen in all orthodontically moved teeth. Conclusions: The orthodontic movement did not favor tissue response in all replanted teeth, regardless of the experimental periods.
\end{abstract}

Keywords: avulsed tooth; replanted tooth; orthodontic movement; in vivo; rats

\section{Introduction}

The early loss of an incisor can cause severe psychological and functional damage such as aesthetic loss, occlusion, and poor speech since avulsions involving permanent teeth are commonly seen in youth, where root development is incomplete [1]. Immediate dental replantation is considered the 
most appropriate clinical procedure for achieving a successful tooth avulsion treatment, although it is not always possible [2].

The sequelae regarding the replantation of the avulsed teeth involve surface resorption, inflammatory resorption, replacement resorption, and dentoalveolar ankylosis [3-7]. Avulsion of one or more teeth requires emergency care by the dentist [8], where the first choice is the possibility of replanting the avulsed tooth to restore esthetics and function $[9,10]$.

Some previous studies have suggested that there is an association of dental trauma and malocclusion [11-17]. Increased overjet (more than $4 \mathrm{~mm}$ ), poor labial sealing, short upper lip, Angle Class II malocclusion, and mouth breathing can represent significant characteristics predisposing upper incisor traumatism, and it was the most common factors related to dental trauma [16]. Patients with these characteristics are also candidates for orthodontic treatment and often look for treatment with a history of prior dental trauma.

As accidental dental trauma commonly occurs in children, some may need orthodontic treatment for malocclusion correction soon. In the literature, clinical studies report that after four or five months of follow-up, slightly or moderately traumatized periodontal ligament can be orthodontically moved with a similar prognosis as the non-traumatized tooth [18]. However, there are no pre-clinical or clinical studies in the literature with teeth that were severely traumatized (tooth avulsion) and then submitted to orthodontic treatment. A previous study concluded that orthodontic treatment purposes must be reviewed when the patient shows evident root resorptions [18]. These authors advised a thorough examination of the root outline, observing the occurrence of any root resorptions, surface concavities, and malformations, since teeth with these characteristics may be severely reabsorbed during treatment.

A significant number of animal studies seeking successful experimental treatments for tooth avulsion is available in the literature [19-24], but not with orthodontic movement. For the first time, the present study aimed to evaluate the tissue response of orthodontic movement on avulsed teeth after $30 \mathrm{~min}$ of replantation.

\section{Materials and Methods}

Animal experiments and breeding were performed under conditions approved by the Institutional Review Board of the Universidade de São Paulo-Ribeirão Preto (Protocol number 05.1.1174.53.0), in compliance with the National Institute of Health (NIH) Guide for Care and Use of Laboratory Animals and with Brazilian legislation on animal use. This study was conducted according to the guidelines of the 3R's Program (Reduction, Refinement, Replacement) and reported according to the ARRIVE [25] guidelines (Animal Research: Reporting of In Vivo Experiments) with regard to relevant items and Planning Research and Experimental Procedures on Animals: Recommendations for Excellence (PREPARE) [26].

The sample size calculation was performed using the G Power software by the ANOVA test (Analysis of Variance).

After the calculus, a sample size of at least 14 rats in each group was required to achieve $80 \%$ power at a significance level of 5\%. This value was adjusted for $5 \%$ attrition and was allocated around 15 rats per group [27] with a total of 60 animals (Table 1). Sixty male Wistar rats (Rattus norvegicus, Albinus) weighing 250-300 g was used. The animals' age was approximately 90 days, and they were obtained from the bioterium of the Universidade de São Paulo Dentistry School at Ribeirão Preto.

Table 1. Sixty rats divided into four experimental groups according to the experimental periods after replantation and subsequently orthodontic movement.

\begin{tabular}{cccc}
\hline Groups & $n$ & Orthodontic Movement & Euthanasia \\
\hline 1 & 15 & - & 30 days after onset of experiment \\
2 & 15 & 30 days after reimplantation & 7 days after orthodontic movement \\
3 & 15 & - & 60 days after onset of experiment \\
4 & 15 & 60 days after reimplantation & 7 days after onset of orthodontic movement \\
\hline
\end{tabular}


During the experiment, the animals were kept in individual cages $(n=2)$ specially prepared for this purpose. The rats were daily fed with solid ground rations (Guabi Nutrilabor, Mogiana Alimentos, São Paulo, Brazil) and water was provided ad libitum during the experiment. Vitamin C was supplemented by adding $20 \mathrm{mg}$ of ascorbic acid to the water supply, and the room temperature was kept between $16{ }^{\circ} \mathrm{C}$ and $20^{\circ} \mathrm{C}$. A standard 12-h light-dark cycle was adopted to establish an optimal metabolic cycle. The supervision of animal care, diet, and pre- and post-operative fasting were conducted by a veterinary with experience in rodents.

Before the procedures, the animals received general anesthesia with ketamine hydrochloride $25 \mathrm{mg} / \mathrm{kg}$ (Virbac, Jurubatuba, SP, Brazil) and xylazine hydrochloride $1 \mathrm{mg} / \mathrm{Kg}$ (FortDodge, São Cristovão, RJ, Brazil), both intraperitoneal [28].

The left maxillary incisors of all animals were extracted in a non-traumatic technique. The dental papilla and the enamel organ were removed from each extracted tooth by using a \#11 scalpel blade (Bard Parker, Caledonia, MI, USA), according to previous studies that aimed to interrupt the continuous growing of the tooth $[29,30]$. Then, they were immediately stored in milk for $30 \mathrm{~min}$.

After this period of time, each tooth had its most coronal portion wrapped with gauze, and the pulp tissue was extirpated through a retrograde via with a \#15 Hedström file (25 mm, Maillefer, Dentsply, MI, USA). The root canal was irrigated with $0.9 \%$ sodium chloride solution, and a syringe with a $25 \times 27 \mathrm{~mm}$ needle was used for aspirating the residues and dried with absorbent paper points. The same root canal was filled with saturated calcium hydroxide paste. Immediately after the root filling, the teeth were replanted into their respective socket [31].

According to the purpose of the present study, the animals were randomly divided into four groups consisting of 15 animals each, as follows:

After replantation, all animals received a single intramuscular 20,000 UI Penicillin G Procaine dose (Wycillin R 400,000 UI-Fontoura-Wyeth, São Paulo, SP, Brazil). The orthodontic movement was achieved by using an appliance made of 0.016 " cross-sectioned round stainless wire in order to promote inclined dental movement and a diastema between both upper incisors (Figure 1). A double coil spring of $1.5 \mathrm{~mm}$ diameter was medially positioned $7 \mathrm{~mm}$ from the upper incisors in an anteroposterior sense and $1 \mathrm{~mm}$ from the bony palate. Two incisor-oriented parallel wires were separated from each other in $0.5 \mathrm{~mm}$ and surrounded the distal faces toward the vestibular direction.

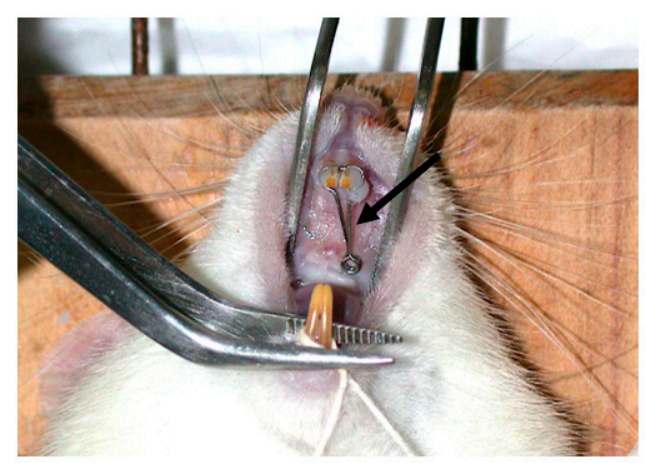

Figure 1. Orthodontic appliance performed with 0.016 " cross-sectioned round stainless wire in order to promote inclined dental movement and a diastema between both upper incisors.

A cavity was made between the two upper incisors and parallel and transversal horizontal grooves along the teeth axis. Grooves were also made buccally, medially, and distally in the central incisors at the interdental papilla apex and the palatine surface. Both hole and grooves were made by using a 0.5 spherical diamond drill mounted on a counter angle and adapted to a low-speed electric motor. The grooves enabled both better adjustment and attachment of the orthodontic appliance. The coil spring was attached to the incisors with a bonding composite (TPH Spectrum, Dentsply). A dynamometer was used for assessing and confirming the activated spring at $0.5 \mathrm{~N}$. The inserted coil 
springs were checked daily in terms of attachment, stability, and corrections to prevent injury to the animal's buccal mucous membrane.

After 37 and 67 days, the animals were euthanized with an overdose of general anesthesia, and the bone block containing the replanted tooth was removed, fixed in 10\% neutral formaldehyde solution for one week, and then submitted to the histological process, cut into $5 \mu \mathrm{m}$, and stained with Hematoxylin and Eosin (HE) for histological and histomorphometric evaluation.

\subsection{Histomorphometric Analysis}

The histomorphometric evaluation of the root surface was performed according to the modified method described by Andreasen [32]. A grid consisting of four lines intersecting each other was positioned over the cross-sectioned incisor root photomicrograph. The center of the grid superimposed the geometric center of the pulp cavity, and the vertical line superimposed the greatest buccal-lingual diameter of the root. In this manner, histological changes in the supporting periodontium could be evaluated through the intersections of the four lines with the root surface. A blinded observer performed the histological and histomorphometric evaluation (Figure 2).

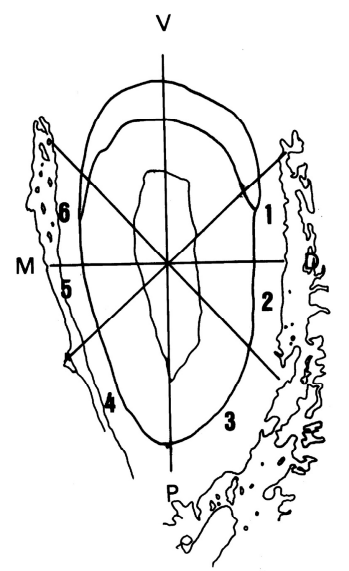

Figure 2. The six root areas evaluated the cross-sectioned incisor root. A grid mask was superimposed to the geometric center of pulp cavity to evaluate the biological response of the periodontium according to the experimental period.

During the orthodontic movement, the moved teeth presented inclination according to pressure (regions 1, 2, and 3) and tension (regions 4, 5, and 6), totalizing 45 areas in the pressure side and 45 areas in the tension side of each of the groups.

The periodontal response characteristics were classified according to the following periodontal parameters:

(a) Repair: small resorption areas repaired by cement neoformation;

(b) Root resorption: inflammatory resorption areas with the presence of an inflammatory infiltrate in addition to the multinucleated cells; and

(c) Ankylosis: deposition of bone tissue juxtaposed to the cementum layer.

Cross-sectioned incisors and the middle portion of the supporting periodontium were used for statistical analysis. Cervical and apical regions were not used as the cervical is frequently traumatized during the extraction, and the apical had the dental papilla removed.

\subsection{Statistical Analysis}

Descriptive statistics were performed to evaluate the data obtained in the histomorphometric analysis. The association between histological evaluation and the experimental groups was statistically analyzed with Fisher's exact test, with a significance level of 5\%. 


\section{Results}

The results showed that the orthodontic movement did not favor the periodontal ligament repair in both experimental periods. The histological evaluation of both experimental periods showed better results for the tension side (areas 4, 5, and 6) compared to the pressure side (areas 1, 2, and 3). Three regions of each animal/side were evaluated $(n=45)$. These histological findings are shown in Table 2 (pressure side) and Table 3 (tension side).

Table 2. Histological evaluation of the pressure side of all groups.

\begin{tabular}{|c|c|c|c|c|c|c|c|c|}
\hline \multirow{3}{*}{ Groups } & \multirow{2}{*}{\multicolumn{2}{|c|}{ Total }} & \multicolumn{6}{|c|}{ Histological Evaluation of the Pressure Side } \\
\hline & & & \multicolumn{2}{|c|}{ Repair } & \multicolumn{2}{|c|}{ Root Resorption } & \multicolumn{2}{|c|}{ Ankylosis } \\
\hline & $n$ & $\%$ & $n$ & $\%$ & $n$ & $\%$ & $n$ & $\%$ \\
\hline 1 (30 days-without movement) & 45 & 100 & 15 & 33.3 & 30 & 66.7 & 0 & 0.0 \\
\hline 2 (30 days-with movement) & 45 & 100 & 0 & 0.0 & 36 & 80.0 & 9 & 20.0 \\
\hline 3 (60 days-without movement) & 45 & 100 & 33 & 73.3 & 0 & 0.0 & 12 & 26.7 \\
\hline 4 (60 days-with movement) & 45 & 100 & 0 & 0.0 & 28 & 62.2 & 17 & 37.8 \\
\hline Total & 180 & 100 & 48 & 26.7 & 94 & 52.2 & 38 & 21.1 \\
\hline
\end{tabular}

Table 3. Histological evaluation of the tension side of all groups.

\begin{tabular}{|c|c|c|c|c|c|c|c|c|}
\hline \multirow{3}{*}{ Groups } & \multirow{2}{*}{\multicolumn{2}{|c|}{ Total }} & \multicolumn{6}{|c|}{ Histological Evaluation in the Tension Side } \\
\hline & & & \multicolumn{2}{|c|}{ Repair } & \multicolumn{2}{|c|}{ Root Resorption } & \multicolumn{2}{|c|}{ Ankylosis } \\
\hline & $n$ & $\%$ & $n$ & $\%$ & $n$ & $\%$ & $n$ & $\%$ \\
\hline 1 (30 days-without movement) & 45 & 100 & 14 & 31.1 & 31 & 68.9 & 0 & 0.0 \\
\hline 2 (30 days-with movement) & 45 & 100 & 0 & 0.0 & 29 & 64.4 & 16 & 35.6 \\
\hline 3 (60 days-without movement) & 45 & 100 & 31 & 68.9 & 0 & 0.0 & 14 & 31.1 \\
\hline 4 (60 days-with movement) & 45 & 100 & 0 & 0.0 & 24 & 53.3 & 21 & 46.7 \\
\hline Total & 180 & 100 & 45 & 25 & 84 & 46.7 & 51 & 28.3 \\
\hline
\end{tabular}

By applying Fisher's exact test to the histological evaluations, it was observed that the results were statistically significant in all groups without orthodontic movement regardless of the post-replantation periods of 30 or 60 days. In terms of percentage, better results regarding the periodontal ligament repair were observed in those groups following 60 days of replantation (Table 4).

Table 4. Effect of the orthodontic movement on the histological evaluation after 30 min of replantation (regions 1-6).

\begin{tabular}{cccccccccc}
\hline $\begin{array}{c}\text { Post-Replantation } \\
\text { Period }\end{array}$ & $\begin{array}{c}\text { Histological } \\
\text { Evaluation }\end{array}$ & \multicolumn{2}{c}{ Orthodontic Movement } & \multicolumn{2}{c}{ Total } & \multicolumn{2}{c}{ No } \\
& & $n$ & $\%$ & $n$ & $\%$ & $n$ & $\%$ & \\
\hline \multirow{3}{*}{30 days } & Repair & 29 & 32.2 & 0 & 0.0 & 29 & 16.1 & \\
& No repair * & 61 & 67.8 & 90 & 100 & 151 & 83.9 & $<0.001$ \\
& Total & 90 & 100 & 90 & 100 & 180 & 100 & \\
& Repair & 64 & 71.1 & 0 & 0.0 & 64 & 35.6 & \\
& No repair * & 24 & 26.7 & 90 & 100 & 116 & 64.4 & $<0.001$ \\
& Total & 90 & 100 & 90 & 100 & 180 & 100 & \\
\hline
\end{tabular}

${ }^{*}$ represents a statistically significant difference between groups at same experimental time point.

The group without orthodontic movement and after 60 days of replantation (Figure 3) presented $71.1 \%$ of periodontal ligament repair (Figure 3). Comparing the pressure and tension sides concerning the experimental periods, $80 \%$ of root resorption on the pressure side was observed after 30 days of replantation (Figure $4 \mathrm{~A}, \mathrm{~B}$ ) and $62.2 \%$ after 60 days, and 20\% of ankylosis (Figure $5 \mathrm{~A}, \mathrm{~B}$ ) after 30 days versus $37.8 \%$ after 60 days. 


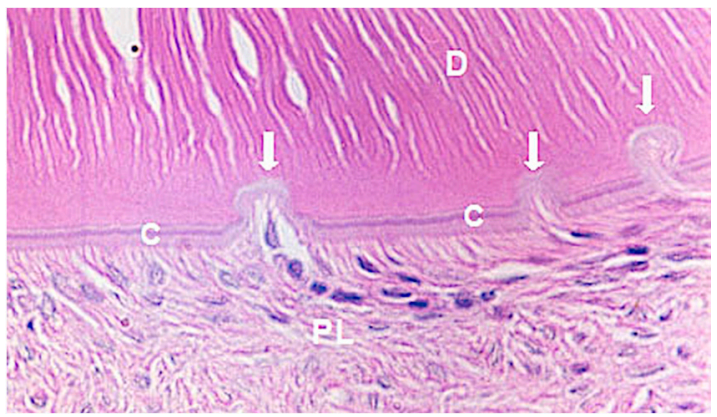

Figure 3. Photomicrographic of the repaired area of the periodontal ligament. Arrows indicate inactive resorption lacunae with neoformation of cement; C-cement; D-dentin; PL-periodontal ligament. Magnification: 40X; Stain: HE. HE: Hematoxilin and Eosin.
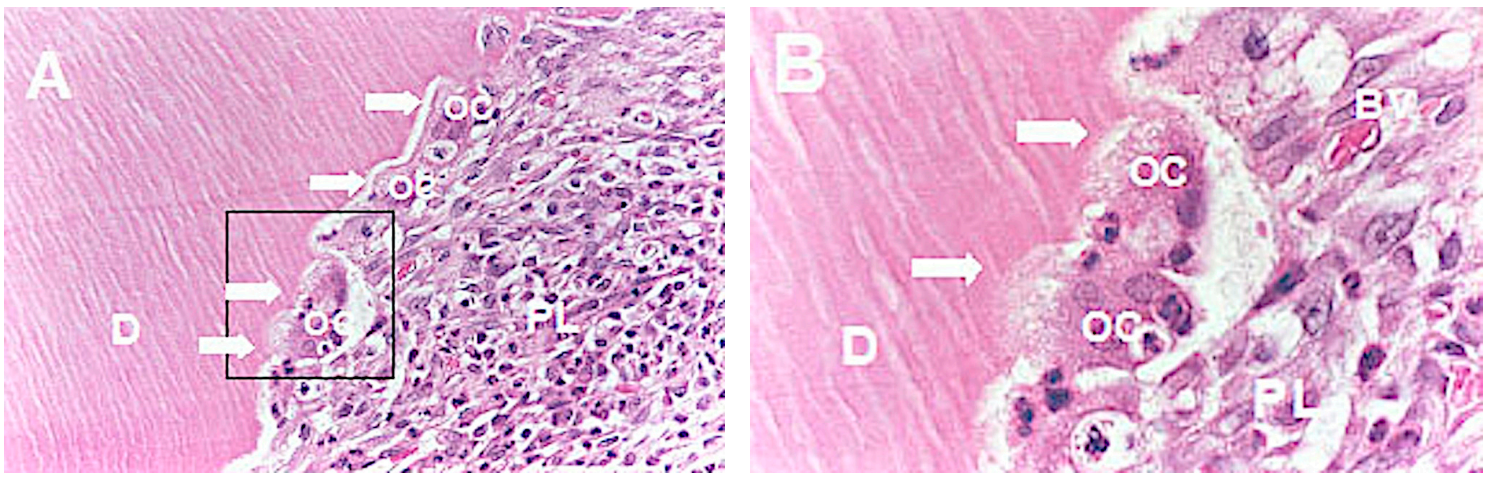

Figure 4. Photomicrographs of tooth presenting root resorption. (A) Inflammatory infiltrate in the periodontal ligament and inflammatory resorption with osteoblasts in the Howship's lacunae. Arrows indicate active resorption lacunae (HE-40X). (B) Active osteoblasts in detail. Arrows indicate ruffled border (HE-100X). OC-osteoclasts; D-dentine; PL-periodontal ligament; BV-blood vessel.
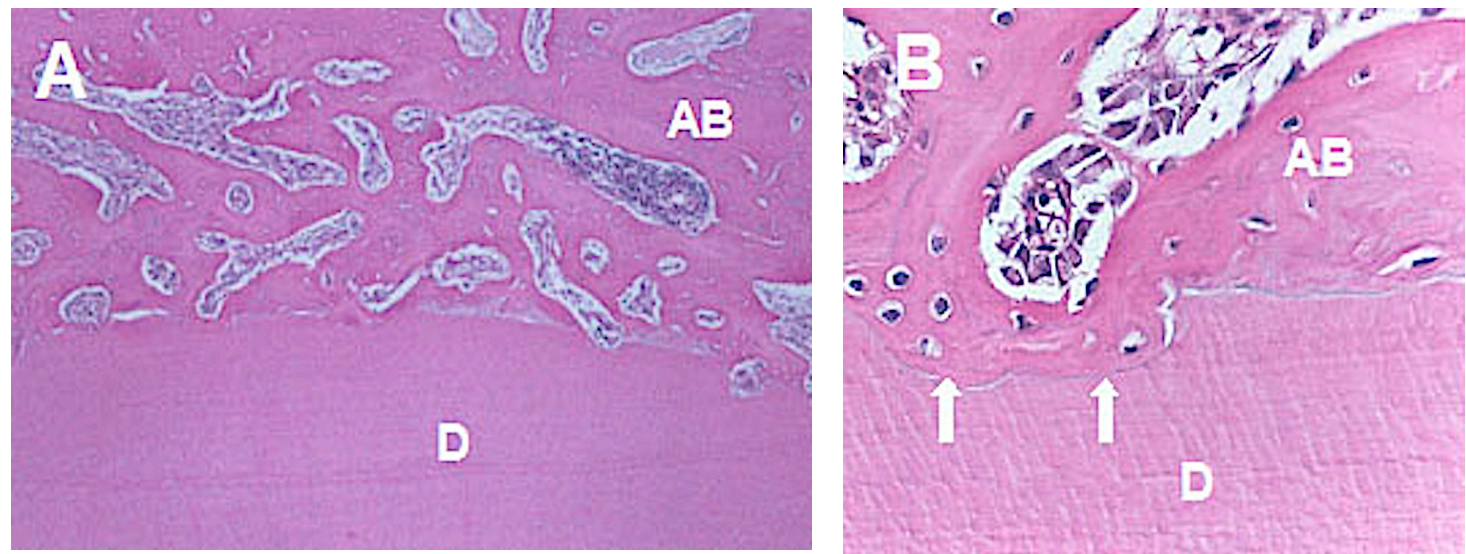

Figure 5. Photomicrograph of tooth presenting ankylosis. (A) ample view of ankylosis (HE-40X).

(B) replacement resorption in detail with bone tissue formation (HE-100X). AB-alveolar bone; D-dentine.

\section{Discussion}

An adequate moment for submitting traumatized teeth to orthodontic movement is not known. Dental trauma promotes damage to the cementoblast layer as well as the extended areas without cementoblasts. The surrounding osteoblasts can also replace the cementoblasts and assume their phenotype and functions efficiently [4].

The orthodontic movement may represent another injury for those previously traumatized because the controlled areas consisting of cementoblast-like osteoblasts can be replaced by osteoremodeling 
units (clasts, osteoblasts, and macrophages) and start an ankylosis process [32]. The extra-alveolar period and the storage medium in which the tooth was kept before replantation is an important factor in allowing the survival and regeneration of the damaged periodontium [33]. Replacement of avulsed teeth is time-dependent, the earlier the tooth is replaced, the better the prognosis.

In this study, all replanted teeth were stored for $30 \mathrm{~min}$ in whole milk. A previous study concluded that whole milk and soymilk favored the periodontal repair process of replanted teeth in rats when associated with laser photobiomodulation [2]. Another study speculated that 20 min of extraoral dry time is detrimental to the periodontal ligament cells as 60 or $90 \mathrm{~min}$ of extraoral dry time [33].

However, a recent study showed that the immediate application of mild and controlled orthodontic forces was not detrimental to the periodontal healing of teeth replanted after 20 min of extraoral dry time, although no significant improvement in periodontal healing was observed [34].

The histological evaluation of all the replanted teeth without orthodontic movement had better results regarding periodontal ligament repair than the replanted teeth with orthodontic movement; this result corroborates the findings by Brin et al. [35]. This study observed a higher incidence of root resorption on the pressure side; these results were also observed in previous studies $[4,9,22]$.

Concerning the tension side, the root regions had $64.4 \%$ of root resorption after 30 days versus $53.3 \%$ after 60 days, and $35.6 \%$ of ankylosis after 30 days versus $46.7 \%$ after 60 days, thus suggesting a higher incidence of root resorption for both experimental periods, despite the lower 60-day values. Ankylosis was also observed in a more significant number of root regions after 60 days. Similar results were found in the literature [5]. Therefore, according to the data described above, the more extended post-replantation period is indicative of better periodontal conditions for orthodontic movement in cases of severe traumatism, although longevity was not indicated.

The lack of periodontal ligament repair in all studied groups after either 30 or 60 days of replantation does not recommend the start of orthodontic treatment. However, it was seen in the literature that the immediate application of mild and controlled orthodontic forces was not detrimental to the periodontal healing of the replanted teeth [34]. Parameters determining the most suitable moment for submitting traumatized teeth to orthodontic movement can be found in the literature: for slight or moderate dental traumatism, 3-6 months of observation should be considered, and if periodontal conditions are reasonable, the orthodontic force can be applied; for severe dental traumatism, one year of observation should be considered; if periodontal conditions are clinically and radiographically normal, the orthodontic force can be used [36-38]. Finally, orthodontic treatment is not recommended until the periodontal recovery of the replanted tooth is complete.

This study used a pre-clinical model with rodents. It is known that the incisors of rats are continuously growing teeth and that for this reason, the results of the study could not be extrapolated to humans. However, previous studies have shown that removing the tooth papillae and enamel organ of the rat's tooth would interrupt its growth, making it more similar to the human tooth's behavior. It should be considered that the results obtained in groups without OM demonstrated a tendency of tissue repair, and therefore OM should be delayed.

The clinician should know that traumatized teeth with signs of root resorption before the orthodontic treatment are at a high risk of increased root resorption as a result of orthodontic movement [39,40].

Clinical studies should be conducted with the purpose of elaborating guidelines on the proper timing of orthodontic force application after short- and long-term replantation. These guidelines would be helpful in guiding orthodontists who are initiating orthodontic treatment in patients with a history of replanted teeth.

\section{Conclusions}

Based on the results found in this study, it can be suggested that:

The orthodontic movement did not favor the periodontal ligament repair in both experimental periods.

After 30 days of replantation, the orthodontic movement did not interfere with the root resorption; however, after 60 days, the orthodontic movement favored the root resorption. 
The orthodontic movement favored the ankylosis after 30 and 60 days of replantation.

In the group without orthodontic movement, the periodontal ligament repair increased along the experimental periods. The root resorption decreased from 30 to 60 days, and the ankylosis was observed only after 60 days of replantation.

Author Contributions: Conceptualization, J.d.A.C.-M., M.D.C.-M., and M.B.S.S.; Methodology, J.d.A.C.-M., M.D.C.-M., M.B.S.S., A.T.N.N.A., and A.C.d.O.R.; Software, J.d.A.C.-M., and P.M.; Validation, J.d.A.C.-M., M.D.C.-M., A.T.N.N.A., C.F.d.A.B.M., A.C.d.O.R., J.P.e.C.-N., and P.M.; Formal analysis, J.d.A.C.-M., A.C.d.O.R., M.D.C.-M., and M.B.S.S.; Investigation, J.d.A.C.-M., M.B.S.S., and A.T.N.N.A.; Resources, P.M., and C.F.d.A.B.M.; Data curation, J.d.A.C.-M., M.D.C.-M., A.T.N.N.A., and M.B.S.S.; Writing—original draft preparation, J.d.A.C.-M., J.P.e.C.-N., and M.D.C.-M; Writing-review and editing, J.d.A.C.-M., J.P.e.C.-N., A.C.d.O.R., and M.D.C.-M.; Visualization, C.F.d.A.B.M., J.d.A.C.-M., M.D.C.-M., A.C.O.R., M.B.S.S., A.T.N.N.A., and P.M.; Supervision, M.B.S.S., A.T.N.N.A., and A.C.d.O.R.; Project administration, P.M., C.F.d.A.B.M., and J.P.e.C.-N.; Funding acquisition, M.B.S.S., A.C.d.O.R., P.M., and C.F.d.A.B.M. All authors have read and agreed to the published version of the manuscript.

Funding: This research received no external funding.

Conflicts of Interest: The authors declare no conflict of interest.

\section{References}

1. Adams, F.R. Traumatized and fractured young teeth. JADA 1944, 31, 41-248. [CrossRef]

2. Matos, F.S.; Godolphim, F.J.; Correia, A.M.O.; Junior, R.L.C.A.; Paranhos, L.R.; Rode, S.M.; Ribeiro, M.A.G. Effect of laser photobiomodulation on the periodontal repair process of replanted teeth. Dent. Traumatol. 2016, 32, 402-408. [CrossRef] [PubMed]

3. Andreasen, J.O. Challenges in clinical dental traumatology. Endod. Dent. Traumatol. 1985, 1, 45-55. [CrossRef] [PubMed]

4. Andreasen, J.O.; Lovschall, H. Response of Oral Tissues to Trauma. In Textbook and Color Atlas of Traumatic Injuries to the Teeth, 4th ed.; Andreasen, J.O., Andreasen, F.M., Andersson, L., Eds.; Blackwell/Munksgaard: Oxford, UK, 2007; pp. 217-254.

5. Hasanuddin, S.; Sharada Reddy, J. Sequelae of delayed replantation of maxillary permanent incisors after avulsion: A case series with 24-month follow-up and clinical review. J. Indian Soc. Pedod. Prev. Dent. 2018, 36, 410-416. [CrossRef] [PubMed]

6. Krug, R.; Kremeier, K.; Krastl, G. Long-term retention of avulsed maxillary permanent incisors replantes after prolonged non-physiological storage. Dent. Traumatol. 2019, 35, 147-152. [CrossRef] [PubMed]

7. Ruizhen, F.; Siyi, L.; Lei, G.; Li'an, W. Decoronation management of the replacement resorption after delayed replantation of avulsed teeth-Case report with 4-year follow-up. Hua Xi Kou Qiang Yi Xue Za Zhi 2017, 35, 665-669. [PubMed]

8. Gonçalves, P.S.P.; Ionta, F.Q.; Rios, D.; Oliveira, D.S.B.; Couto-Filho, C.E.G.; Honório, H.M. Reimplantation of na avulsed mature permanente toorh after 6 days: A 1-year follow-up. Gen. Dent. 2018, 66, 71-75.

9. Mackie, I.C. The avulsed tooth. Br. Dent. J. 1987, 163, 359. [CrossRef]

10. Walia, T.; Chandwani, N. Long-term management of an ankylosed young permanent incisor replanted within $2 \mathrm{~h}$ of avulsion: A case with a 10-year follow-up. J. Indian Soc. Pedod. Prev. Dent. 2019, 37, 99-106. [CrossRef]

11. Järvinen, S. Incisal overjet and traumatic injuries to upper permanent incisors. A retrospective study. Acta Odontol. Scand. 1978, 36, 359-362. [CrossRef]

12. Brin, I.; Ben-Bassat, Y.; Heling, I.; Brezniak, N. Profile of an orthodontic patient at risk of dental trauma. Endod. Dent. Traumatol. 2000, 16, 111-115. [CrossRef] [PubMed]

13. Burden, D.J. An investigation of the association between overjet size, lip coverage and traumatic injury to maxillary incisors. Eur. J. Orthod. 1995, 17, 513-517. [CrossRef] [PubMed]

14. Forsberg, C.M.; Tedestam, G. Etiological and predisposing factors related to traumatic injuries to permanent teeth. Swed. Dent. J. 1993, 17, 183-190. [PubMed]

15. Petti, S.; Tarsitani, G. Traumatic injuries to anterior teeth in Italian schoolchildren: Prevalence and risk factors. Endod. Dent. Traumatol. 1996, 12, 294-297. [CrossRef] 
16. Antunes, L.A.; Gomes, I.F.; Almeida, H.M.; Silva, E.A.; Calasans-Maia, J.A.; Antunes, L.S. Increased overjet is a risk factor for dental trauma in preschool children. Indian J. Dent. Res. 2015, 26, 356-360. [CrossRef] [PubMed]

17. Arrai, G.P.; Rossi-Fedele, G.; Dogramaci, E.J. The association of overjet size and traumatic dental injuries-A systematic review and meta-analysis. Dent. Traumatol. 2019, 35, 217-232. [CrossRef]

18. Malmgren, O.; Goldson, L.; Hill, C.; Orwin, A.; Petrini, L.; Lundberg, M. Root resorption after orthodontic treatment of traumatized teeth. Am. J. Orthod. 1982, 82, 487-491. [CrossRef]

19. Abrams, R.A. Replantation of an avulsed incisor: Case report. Quintessence Int. Dent. Dig. 1978, 9, 85-87.

20. Abrams, R.A. Tooth replantation: 11-year follow up. Aust. Dent. J. 1987, 6, 427-429. [CrossRef]

21. Myers, H.I.; Nassimben, L.; Alley, J.; Gehsig, J. Replantation of teeth in the hamster. Oral Surg. 1954, 7, 116-1129. [CrossRef]

22. Skoglund, A. Pulpal changes in replanted and autotransplanted apicoectomized mature teeth of dogs. Int. J. Oral Surg. 1981, 10, 111-121. [CrossRef]

23. Andreasen, J.O.; Kristerson, L. The effect of extra-alveolar root filling with calcium hydroxide on periodontal healing after replantation of permanent incisors in monkeys. J. Endod. 1981, 7, 349-353. [CrossRef]

24. Blomlöf, L.; Lindskog, S.; Andersson, L.; Hedström, K.G.; Hammarström, L. Storage of experimentally avulsed teeth in milk prior to replantation. J. Dent. Res. 1983, 62, 912-916. [CrossRef] [PubMed]

25. Kilkenny, C.; Brown, W.J.; Cuthill, I.C.; Emerson, M.; Altman, D.G. Improving bioscience research reporting: The ARRIVE guidelines for reporting animal research. Vet. Clin. Pathol. 2012, 41, 24-31. [CrossRef] [PubMed]

26. Smith, A.J.; Clutton, R.E.; Lilley, E.; Hansen, K.E.A.; Brattelid, T. PREPARE: Guidelines for planning animal research and testing. Lab Anim. 2018, 52, 135-141. [CrossRef] [PubMed]

27. Charan, J.; Kantharia, N.D. How to calculate sample size in animal studies? J. Pharmacol. Pharmacother. 2013, 4, 302-306. [CrossRef]

28. Soma, L.R. Anesthetic and analgesic considerations in the experimental animal. In The Role of Animals in Biomedical Research; Annals of New York Academy Science: New York, NY, USA, 1983; Volume 406, pp. $32-47$.

29. Okamoto, T. Reimplante de dentes de crescimento contínuo após ressecção da papila dental e órgão do esmalte. Estudo Histológico. Rev. Ass. Paul. Cirurg. Dent. 1976, 30, 382-395.

30. Okamoto, T.; Niccoli-Filho, W.; Sonode, C.K.; Martins, A.P.; Souza, R. Immediate replantation of maxillary incisors in rats: Effects of tooth immersion in sodium fluoride and subsequent removal of the periodontal ligament. Braz. Dent. J. 1999, 10, 73-79.

31. Saito, C.T.M.H.; Guinelli, J.L.; Panzarini, S.R.; Garcia, V.G.; Okamoto, R.; Okamoto, T.; Sonoda, C.K.; Poi, W.R. Effect of low-level laser therapy on the healing process after tooth replantation: A histomorphometrical and immunohistochemical analysis. Dent. Traumatol. 2011, 27, 30-39. [CrossRef]

32. Andreasen, J.O. Experimental dental traumatology: Development of a model for external root resorption. Endod. Dent. Traumatol. 1987, 3, 269-287. [CrossRef]

33. Barbizam, J.V.B.; Massarwa, R.; Silva, L.A.B.; Silva, R.A.B.; Nelson-Filho, P.; Consolaro, A.; Cohenca, N. Histophatological evaluation of the effects of variable extraoral dry times and enamel matrix proteins (Enamel Matrix Derivatives) application on replanted dog's teeth. Dent. Traumatol. 2015, 31, 29-34. [CrossRef] [PubMed]

34. Gregorio, C.; Cohenca, N.; Romano, F.; Pucinelli, C.M.; Cohenca, N.; Romero, M.; Lucisano, M.P.; Silva, R.A.B.; Silva, L.A.B. The effect of immediate controlled force on periodontal healing of teeth replanted after short dry time in dogs. Dent. Traumatol. 2018, 34, 336-346. [CrossRef] [PubMed]

35. Brin, I.; Ben-Bassat, Y.; Heling, I.; Engelberg, A. The influence of orthodontics treatment on previously traumatized permanent incisors. Eur. J. Orthod. 1991, 13, 372-377. [CrossRef] [PubMed]

36. Malmgren, O.; Malmgren, B.; Goldson, L. Orthodontic management of the traumatized dentition. In Textbook and Color Atlas of Traumatic Injuries to the Teeth, 4th ed.; Andreasen, J.O., Andreasen, F.M., Andersson, L., Eds.; Blackwell Munksgaard: Oxford, UK, 2007; pp. 669-715.

37. Bauss, O.; Freitag, S.; Röhling, J.; Rahman, A. Influence of orthodontic intrusion on pulpal vitality of previously traumatized maxillary permanent incisors. Am. J. Orthod. Dentofac. Orthop. 2008, 134, 12-17. [CrossRef] [PubMed]

38. Kindelan, S.A.; Day, P.F.; Kindelan, J.D.; Spencer, J.R.; Duggal, M.S. Dental trauma: An overview of its influence on the management of orthodontic treatment. Part 1. J. Orthod. 2008, 35, 68-78. [CrossRef] [PubMed] 
39. Levander, E.; Malmgren, O. Evaluation of the risk of root resorption during orthodontic treatment: A study of upper incisors. Eur. J. Orthod. 1988, 10, 30-38. [CrossRef]

40. Tondelli, P.M.; Mendonça, M.R.; Cuoghi, O.A.; Pereira, A.L.P.; Busato, M.C.A. Knowledge on dental trauma and orthodontic tooth movement held by a group of orthodontists. Braz. Oral Res. 2010, 24, 76-82. [CrossRef]

(C) 2020 by the authors. Licensee MDPI, Basel, Switzerland. This article is an open access article distributed under the terms and conditions of the Creative Commons Attribution (CC BY) license (http://creativecommons.org/licenses/by/4.0/). 